Ali R. Al-Khatib

BDS, MSc. PhD. (Prof.)

Lamiaa Abdulrhman Hasan

BDS, MSc. (Asst. Lec.)

Nada Nashee Al-Hafidh

BDS, MSc. (Asst. Lec.)

\section{An Overview on the Applications of Finite Element Analysis in Orthodontic}

Depart. of Pedodontic, Ortho. and Preventive Dentistry College of Dentistry, University of Mosul

Depart. of Pedodontic, Ortho. and Preventive Dentistry College of Dentistry, University of Mosul

Depart. of Pedodontic, Ortho. and Preventive Dentistry College of Dentistry, University of Mosul

\footnotetext{
الخلاصة

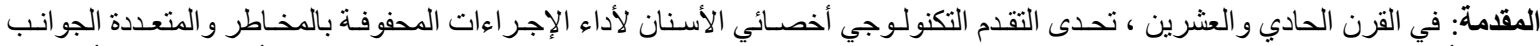

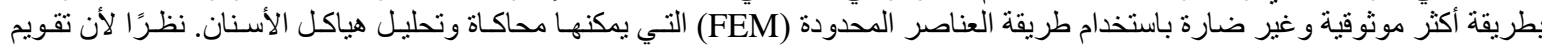

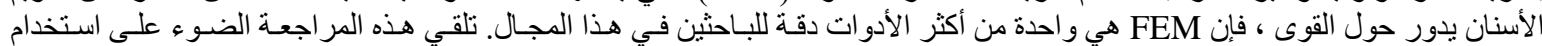

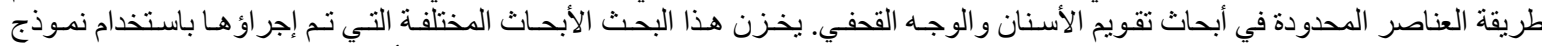

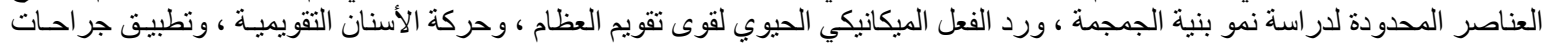
التقويم ، و الغرسات التقويمية.
}

\begin{abstract}
In the 21st era, technological progressions challenged the dental professional to perform extremely risky and multifaceted procedures more reliably and harmless way using the finite element method (FEM) that can simulate and analyze the dental structures. As orthodontic revolve about the forces so FEM is one of the most accurate tools for the researchers in this ground. This review highlights the use of the finite element method in orthodontics and craniofacial research. This stores the different researches performed by using the finite element model to study the growth of the cranial structure, biomechanical reaction to orthopedic forces, orthodontic tooth movement, orthognathic surgeries application, and orthodontic implants
\end{abstract}

Keywords: Finite element analysis, Stress, Orthodontic tool.

Al-Khatib AR., Hasan LA., Al-Hafidh NN. An Overview on the Applications of Finite Element Analysis in Orthodontic. AL-Rafidain Dent J. 2021; 21(2):185-192.

DOI: $10.33899 /$ rdenj.2021.129173.1074 @2020, College of Dentistry, University of Mosul.

Received: 20/12/2020 Sent to Referees: 25/12/2020

Accepted for Publication: 31/1/2021

This is an open access article under the CC BY 4.0 license (http://creativecommons.org/licenses/by/4.0/)

\title{
Finite Element Method
}

The finite element method (FEM) is a a geometric model that results from a definite computerized Analytical tool that estimates the force upon a system a geometric model that deformation and the biomechanical response of results from a definite force upon a system ${ }^{1}$. 
The finite element was firstly introduced in the early 1960s. Most commercial FEM software packages originated in the 1970s like Abaqus and Ansys ${ }^{2}$.

FEM divides the analyzed structure into several partitions (elements). The elements are reconnected at "nodes" resulting in a set of simultaneous algebraic equations at nodes ${ }^{3}$.

\section{Advantages of FEM}

- FEM can be applied to non-linear and linear as well as fluid and solid structural ${ }^{4}$.

- It is a non-destructive technique ${ }^{4}$.

- By utilizing FEM, any biological condition can be simulated to get more accurate results ${ }^{1}$.

- Assess the deformation in a repeatable manner, repeating the analysis does not distress the tested material properties ${ }^{4}$.

- Static and dynamic analysis are conceivable ${ }^{2}$.

- Less effort and time consuming ${ }^{1}$.

- No need for extensive instrumentation ${ }^{4}$.

\section{Shortcomings of FEM}

- Inaccurate details and information will result in misguiding results ${ }^{4}$.

- Human biological structures are extremely challenging for modeling ${ }^{4}$.

- Accurate physical properties should be available ${ }^{4}$.

- Tooth is restrained to the surrounding tissue; this is presumed to be rigid. This assumption will introduce some error ${ }^{4}$.

\section{Application of FEM in orthodontics}

\section{1-Craniofacial growth}

According to Moss et al. ${ }^{5}$, FEM evaluates the cranium finer than previously available.
Diewert and Lozanoff ${ }^{6}$ executed a morphometric study of early human craniofacial development in the median plane through the period of primary palate growth using FE analysis suggested that morphogenetic growth changes in the cranial regions are closely associated with facial regions during primary palate formation.

Montegi et al. ${ }^{7}$ in their study examine the facial skeleton changes with the aims of FEM. The results indicate that mandible growth was mainly in the early human period, and the path of growth directed backward and upward from the mental region to condylar joint.

According to McIntyre et al. ${ }^{8}$, FEM is a sensitive morphometric technique and it can estimate the shape change of the structure under examination, in all directions and at each landmark which is not possible with conventional cephalometric analysis.

\section{2-Periodontal stress and tooth movement}

The biomechanics of orthodontic movement has been explained by many researchers. Tooth movement essentially is governed by stress and strain in periodontal tissue ${ }^{4}$.

Williams and Edmundson ${ }^{9}$ studied the position of the instantaneous center of rotation of a maxillary central incisor using the FEM. It shows that the center of rotation is insensitive to the properties of the surrounding periodontal tissue. The position of the center of rotation is independent of load but dependent on the point of loading. Tanne $\mathrm{K}$ et al ${ }^{10}$ studied the stress in the periodontal tissue that results from orthodontic forces using the FEM. They found out 
that the stresses in the periodontium from a specified level of force were different, depending on the center of rotation of the tooth.

McGuinness et al ${ }^{11}$ found that the quantification of stress in the periodontal ligament is an important concept, as stress in the periodontal ligament is transmitted to the alveolus with subsequent bone remodeling and tooth movement produced by an edgewise appliance. Mestrovic et al ${ }^{12}$ study the tooth movement resulting from orthodontic forces using FEM. They also concluded that the tipping tooth movement is greater if the force is applied more gingivally.

Kojima et $\mathrm{l}^{13}$ studied the difference in initial tooth movement and long-term tooth movement on finite element simulation of maxillary teeth connected with the archwire. According to them the location of the center of resistance could be estimated from the initial tooth movement, assuming the archwire to be a rigid material. Jing et al ${ }^{14}$, evaluated the stress patterns along tooth root, periodontium and surrounding bone during cuspid tipping and bodily movement in four consecutive therapeutic weeks by using 3D FEM.

Despite the increasing request for clear aligners to treat maligned teeth, many concerns about the efficacy for this system in controlling tooth movement. The tooth movement achieved upon aligner therapy differs from tooth movement achieved with traditional fix appliance. Jiang et al ${ }^{15}$ studied tooth behaviors under upper anterior teeth retraction with clear aligner therapy. A three-dimensional model of maxillary teeth with extracted first premolar was constructed for finite element analysis. They found that combining intrusion displacement on aligners led to a tendency of lingual root movement for incisor retraction.

The mechanical environment associated with orthodontic tooth movement and root resorption is more complex than is generally appreciated. In the same region of root, PDL and bone, there can be predominantly compressive stresses in one structure, but tensile stresses in another. Viecilli et $\mathrm{al}^{16}$ analyze the directions of tension and compression within the alveolar bone. An idealized tooth model was constructed with $\mathrm{CAD}$ for finite element stress analysis. They found highest principal stress magnitudes in the root, PDL and alveolar surface occurred predominantly in the longitudinal, radial and hoop directions, respectively. On the "compression" side, the only structure consistently in compression in all directions is the PDL; however, magnitudes are different in different directions.

\section{3-Orthopaedic forces}

Tanne $\mathrm{K}$ et al ${ }^{17}$ through three-dimensional FEA models of the mandible studied orthopaedic chin cup forces biomechanical effects on temporomandibular joint and mandible from. This study indicated that, remodelling of the mandible as a result of chin cup forces used for adolescent individuals with advance mandible. Jafari et al ${ }^{18}$, in their study used 3D FE model of a human dried skull to analyze rapid maxil- 
lary expansion stress distribution within the craniofacial complex. According to this study, the expansive forces are also noticeable within the zygomatic and sphenoid region as well as in the intermaxillary suture.

\section{4-Temporomandibular joint dynamics}

Gupta et $\mathrm{al}^{19}$ used a 3D model to assess the of stress in the temporomandibular joint resulting from mandibular protraction. This study indicates that the tensile stresses noticed in the posterosuperior surface of the mandibular condyle this explains condylar progression in this direction. Also, the tensile stresses are generated in the posterior tissues for the glenoid fossa this explains the higher cellular activity for this area.

Katada et al ${ }^{20}$, used 3D FEM to examine the stresses pattern on the mandible and temporomandibular joint consequential to the unilateral horizontal lengthening of mandibular body and vertical lengthening of the ramus. For the mandibular body lengthening, the stress was seen in the anterior area of the condyle and the condyle tilted backward. Conversely, for ramus lengthening the stress found in the posterior area of the condyle and the condyle tilted forward.

\section{5- Orthognathic surgeries}

In orthognathic surgeries aesthetic is of prime importance as patients are too much concerned about their post-operative facial morphology. The advent of facial 3D simulation models and virtual orthognathic surgery gives the patient and the surgeon a new way to interact with each other.

Chabanas et al ${ }^{21}$, through 3D FE model of face soft tissue predicted facial soft tissue deformations resulting from bone repositioning in maxillofacial surgery. Obaidellah et al ${ }^{22}$, in their paper, designate surgical scheduling, simulation and expectation of facial soft tissue look consequential to mandibular advancement using FEM.

Hasan et al ${ }^{23}$ deliberate the biomechanical effect of distractor force direction for mandibular corpus distraction osteogenesis. They found that the maximum von Mises stress, $\mathrm{x}$ and $\mathrm{z}$ displacement were associated within force parallel to the inferior border of the mandible.

Al-Khatib et al ${ }^{24}$ found that Male and female models showed no significant difference for Von Mises stress value and distribution with the same force that associated with distraction osteogenesis of ascending ramus lengthening. The displacement was higher for males than females.

\section{6- Orthodontic implants}

Mini screws and mini-implants are being widely used as Anchorage unite in orthodontic treatment.

Gallas et al ${ }^{25}$, examined 3D bone and implant FE model. Their study presented that the stresses were always concentrated around the cervical region. Jiang et al ${ }^{26}$, carried out a finite element model to assess orthodontic miniimplant differences in the diameter and length 
and to categorize their optimal choices for the maxillary posterior region. They found out that diameter exceeding $1.5 \mathrm{~mm}$ in combination with the longest length in the safety range was the optimal biomechanical choice.

Qie et al ${ }^{27}$. study aim to explain the biomechanical effects of mutual loading of upper anterior teeth and posterior implants with the sliding method for en-masse anterior teeth retraction.

\section{7-Brackets and wire designs}

The FEA diminishes the need for samples and workshop experimentation and allows more design options to be tested easily. Ghosh et al ${ }^{28}$, compared six commercially available ceramic brackets with different designs, FEM was used in stress analysis of them subjected to various forces. They found out that stresses were concentrated at corners, edges and other areas of abrupt change in the shape of the bracket.

Huang et al ${ }^{29}$ using the FEM, studied the torque abilities of conventional and selfligating brackets. According to their study, the active clip of the Speed bracket diminishes torque performance but concurrently lowers the torque moment considerably below the active moment.

Kawamura et al ${ }^{30}$ found that as archwire size was diminished lingual tipping of the incisors was detected using a3D FEM.

Shyagali et $\mathrm{al}^{31}$ study the difference in stresses generated in the bracket-cement-tooth system utilizing a three-dimensional finite element model. They found Adjusting the bracket base mesh by changing the distance of the mesh significantly effects the sum of stress generated in the bracket-cement tooth band.

Knox et $\mathrm{al}^{32}$ utilize a 3D dimensional finite element model to evaluate the stresses in the bracket-cement-tooth band when the physical and geometric properties of cement are varied. They found that the physical properties and thickness of the cement lute and the shape of the cement lute periphery contribute to the stress distribution within the bracket-cementtooth band.

\section{CONCLUSIONS}

FEM provides a new pathway of research with less time, money, animal study models and experiments. Orthodontists can investigate about various things by mean of FEM. Although FEM does not exactly simulate the biological structures but at least some of the physical properties can be studied using it. It holds a special importance for orthodontic science concerned around forces and stress distribution.

\section{REFERENCES}

1. Pritam M, Priyam M, Nivedita S, Sah S, Debapreeti M. Finite Element Method: A Research Tool in Orthodontics. J Res Adv Dent 2015;4:3:58-63

2. Likitmongkolsakul $U$, Smithmaitrie $P$, Samruajbenjakun B, Aksornmuang J. Development and Validation of 3D Finite Element Models for Prediction of Orthodontic Tooth 
Movement. Advanced Digital Dentistry.2018.doi.org/10.1155/2018/4927503.

3. Singh J R, Kambalyal P, Jain M, Khandelwal P. Revolution in Orthodontics: Finite element analysis. Journal of International Society of Preventive and Community Dentistry. 2016; Vol. 6, No. 2.

4. Mohammed SD, Desai H. Basic Concepts of Finite Element Analysis and its Applications in Dentistry: An Overview. Journal of Oral Hygiene \& Health.2014; Volume 2 - Issue 5 •

5. Moss M L, Skalak R, Patel H, Sen K, MossSalentijin L, Shinizuka $M$ et al. Finite element method modeling of craniofacial growth. Americal Journal of Orthodontics.1985; 87(6):453-72.

6. Diewert VM, Lozanoff S. A morphometrics analysis of human embryonic craniofacial growth in the median plane during primary palate formation. J Craniofac Genet Dev Biol.1993 Jul-Sep;13(3):147-61.

7. Montegi N, Tsutsumi S, Watatsuki E. A facial growth analysis based on FEM employing three dimensional surface measurement by a rapid laser device. Okajimas Folia Anat Jpn.1996; Mar;72(6):323-8.

8. McIntyre GT., Mossey PA. Size and shape measurement in contemporary Cephalometrics. European Journal of Orthodontics. 2003; 25: 231-42.

9. Williams K R, Edmundson JT. Orthodontic tooth movement analysed by the Finite Element Method. Biomaterials. 1984; Volume 5, Issue 6, 347-351.
10. Tanne K, Sakuda M, Burstone C.J. Threedimensional finite element analysis for stress in the periodontal tissue by orthodontic forces. Americal Journal of Orthodontics and Dentofacial Orthopaedics.1987 Dec;92(6):499-505.

11. McGuinness N, Wilson A N, Jones M, Middleton J, Robertson N R. Stresses induced by edgewise appliances in the periodontal ligament--a finite element study. Angle Orthod.1992;62(1):15-22

12. Mestrovic S, Slaj M, Rajic P. Finite element method analysis of the tooth movement induced by orthodontic forces. Coll. Antropol. 2003;27 suppl.2:17-21.

13. Kojima Y, Fukui H. A finite element simulation of initial movement, orthodontic movement, and the centre of resistance of the maxillary teeth connected with an archwire. European Journal of Orthodontics. 2011. Doi:10.1093/ejo/cjr123.

14. Jiang $\mathrm{T}$, Wu R Y, Wang J K, Wang HH, Tang G H. Clear aligners for maxillary anterior en masse retraction: a 3D finite element study. SCIENTIFIC REPORTS. 2020 10:10156.

15.Viecilli R F, Katona T R, Chen J, Hartsfield J K,; Roberts W. Eugene. Three-dimensional mechanical environment of orthodontic tooth movement and root resorption. American journal of orthodontics and dentofacial orthopedics. 2007.11.023.DOI: 10.1016/j.ajodo.

16. Jing $Y$, Han X,Cheng B, Bai D.Threedimensional FEM analysis of stress distribution in dynamic maxillary canine movement. Chinese Science Bulletin. 2013;58(20) 
17.Tanne K, Lu Y.C, Tanaka E, Sakuda M. Biomechanicalchanges of the mandible from orthopaedic chin cup force studied in a three-24. Al-Khatib A R, Hasan L A, Alrawi M N, dimensional finite element model. European Journal of Orthodontics.1993;15(6):527-33.

18. Jafari A, Shetty K.S, Kumar M. Study of stress distribution and displacement of various craniofacial structures following application of transverse orthopaedic forces- a three- dimensional 25. FEM study. Angle Othodontics. 2003;73:12-20.

19. Gupta A, Kohli V.S, Hazarey P.V, Kharbanda O.P, Gunjal A. Stress distribution in the temporomandibular joint after mandibular protraction: A 3-dimensional finite element method study. Part 1. Americal Journal of Orthodontics and Dentofacial Orthopaedics. 2009;Jun;135(6):737-48

20. Katada H, Arakawa T, Ichimura K, Sueshi K, Sameshima G.T. Stress distribution in mandible and temporomandibular joint by mandibular distraction: A 3-dimensional finite element analysis. Bull Tokya Dent Coll. 2009;50(4):161-68.

21. Chabanas M, Luboz V, Payan Y. Patient specific finite element model of the face soft tissues for computer-assisted maxillofacial surgery. Medical Image Analysis. 2003;7:131-51.

22. Obaidellah U.H, Radzi Z, Yahya N.A, Abu Osmam N.A, Merican A.F. The facial soft tissue simulation of orthognathic surgery using biomechanical model. Biomed 2008:21:751-57.

23. Hasan LA, Al-Sayagh N M, Al-Banaa L R Influence of different orientations and rates of bidirectional distraction osteogenesis of the mandibular corpus: a three-dimensional study. $\mathbf{J}$ Oral Res Special 2019; Issue.;S1:11-14. Alhajar E H. A Finite Element Analysis of Biomechanics in Distraction Osteogenesis of Ascending Ramus Lengthening between Males and Females-A Comparative Study. Journal of Orofacial Sciences. 2020;12:41-6.

5. Gallas M.M, Abeleira M.T, Fernandez J.R, Burguera M. Three-dimensional numerical simulation of dental implants as orthodontic anchorage. European Journal of Orthodontics. 2005;27(1):12-16.

26. Jiang L, Kong L, Li T, Gu Z, Hou R, Duan Y. Optimal selections of orthodontic miniimplant diameter and length by biomechanical consideration: A three-dimensional finite element analysis. Advances in Engineering Software. 2009 Nov;40(11):1124-30.

27. Qie H, Kong L, Zhang F, Li Ch, Lu L, Dou Ch, Shan L Three-Dimensional Finite Element Analysis on En-Masse Retraction of the Maxillary Anterior Teeth With Quantitative Combined Loading Control. J Oral Implantol. 2020;46 (3): 214-220.

28. Ghosh J, Nanda R.S, Duncanson M.G, Currier G.S. Ceramic bracket design: An analysis using the finite element method. American Journal of Orthodontics and Dentofacial Orthopaedics. 1995;108:575-82.

29. Huang Y, Keiliq L, Rahimi A, Reimann S, Eliades T, Jager A et al. Numeric modeling of torque capabilities of self-ligating and conventional brackets. Americal Journal of Ortjodon- 
tics and Dentofacial Orthopaedics. 2009 bracket base and its effects on bond strength. Nov;136(5):638-43. Dental Press J Orthod. 2015 Mar-Apr;20(2):76-

30. Kawamura J, Tamaya N. A finite element 82. analysis of the effects of archwire size on orthodontic tooth movement in extraction space 32. Knox J, Kralj B, Hübsch P F, Middleton J, closure with miniscrew sliding mechanics. ProJones M L. An evaluation of the influence of orthodontic adhesive on the stresses generated gress in Orthodontics.2019. 20:3 in a bonded bracket finite element model. 2001.

31.Shyagali TR, Bhayya DP, Urs CB, SubramaJan;119(1):43-53.

niam $S$. Finite element study on modification of doi:10.1067/mod.2001.110987. 